\title{
Experiências de significação na linguagem: enunciação e ensino de língua materna
}

\author{
Des expériences de signification dans le langage : l'énonciation et l'enseignement \\ de langue maternelle
}

\section{Carmem Luci da Costa Silva}

Universidade Federal do Rio Grande do Sul - UFRGS - Porto Alegre - Rio Grande do Sul - Brasil

\begin{abstract}
Resumo: Este artigo busca responder à questão: como os processos de falarouvir/escrever-ler, avessos um do outro (BENVENISTE, 2012/2014), constituem a criança em aquisição e o aluno em sala de aula na língua materna? Considerando que o falante/escrevente/ouvinte/leitor, ao enunciar-se, faz a passagem da língua ao discurso, defendemos que, nessa passagem, realiza uma experiência única de significação por meio da qual se instaura como sujeito na linguagem. A reflexão embasa-se na teorização de Benveniste (1966/1995; 1974/1989; 2012/2014) sobre linguagem e nos deslocamentos dessa teorização operados por Agamben (2008) em sua Teoria da Infância e por Dessons (2006) em sua discussão sobre a invenção do discurso. Como a língua atualizada em discurso se mostra como interpretante do sistema cultural, buscamos refletir sobre 0 modo como cada falante/escrevente/ouvinte/leitor se inscreve em sua língua-discurso e instancia a cultura de que faz parte. A experiência de conversão da língua em discurso inaugurase no ato de aquisição e registra uma história que não cessa por meio de atos de enunciação falados e escritos e por seus avessos (atos de escuta e de leitura), que inscrevem cada locutor no funcionamento simbólico da linguagem e o fundam como sujeito na sua língua-discurso. A reflexão apresentada pode embasar atividades em sala de aula, centradas na língua em uso, para possibilitar ao aluno continuar a sua história de enunciações e a sua experiência de significação como sujeito na e pela linguagem.
\end{abstract}

Palavras-chave: Enunciação. Aquisição de língua materna. Ensino e aprendizagem de língua materna.

\begin{abstract}
Cet article vise à répondre à la question: comment les processus de parlerentendre/écrire-lire, l'envers l'un de l'autre (BENVENISTE, 2012/2014), constituent-ils l'enfant en acquisition et l'élève en classe dans la langue maternelle ? Étant que le parlant/écrivant/auditeur/lecteur, à chaque 'énonciation, fait le passage de la langue au discours, nous posons que, dans ce passage, il effectue une expérience unique de signification par laquelle il s'instaure comme sujet dans le langage. La réflexion est basée sur la théorie de Benveniste (1966/1995; 1974/1989; 2012/2014) sur le langage et sur les déplacements de cette théorie opérés par Agamben (2008) dans sa Théorie de l'Enfance et par Dessons (2006) dans son étude sur l'invention du discours. Comme la langue, mise à jour en discours, se présente comme l'interprétant du système culturel, on cherche à réfléchir sur la façon dont chaque parlant/écrivant/auditeur/lecteur s'inscrit dans sa langue-discours et instancie la culture dont il fait part. L'expérience de conversion de la langue en discours s'inaugure dans l'acte d'acquisition et enregistre une histoire qui continue à se produire par des actes d'énonciation parlés et écrits et par leurs envers (actes d'écoute et de lecture), qui inscrivent chaque locuteur dans le fonctionnement symbolique du langage et le fondent comme sujet dans sa langue-discours. La réflexion présentée permet baser des activités en classe, centrées dans la langue en emploi, pour permettre à l'élève de poursuivre son histoire d'énonciations et son expérience de signification comme sujet dans et par le langage.
\end{abstract}

Keywords: Énonciation. Acquisition de la langue maternelle. L'enseignement et l'apprentissage de la langue maternelle. 


\section{Palavras iniciais}

A relação de homologia estabelecida por Benveniste (2012/2014) entre falar e ouvir/escrever e ler permite que se reflita sobre a interdependência entre essas modalidades de uso da língua e sobre as mudanças operadas na passagem da língua ao discurso pelos falantes/escreventes/ouvintes/leitores. Para o teórico, ler é o critério da escrita. Consequentemente, ouvir é o critério da fala. Esses atos se constituem como processos interdependentes, considerados, pelo linguista, avessos um do outro. Como esses processos, avessos um do outro, constituem a criança em aquisição e o aluno em sala de aula na língua materna? Esse questionamento é ponto de partida deste artigo.

Tematizar a língua convertida em discurso é pensar na relação homem e linguagem, relação que está sempre sujeita a mudanças. Isso implica adotar um ponto de vista aquisicional enunciativo para pensar que o aluno, a cada nova experiência de uso da língua, ressignifica o fato de que é um ser falante, um ser ouvinte, um ser escrevente e um ser leitor. Por adotar esse ponto de vista, concebemos que a aquisição tanto da enunciação falada quanto da escrita é processo contínuo e inacabado. Isso porque defendemos, com Benveniste, que "todo homem inventa sua língua e a inventa durante toda sua vida. $\mathrm{E}$ todos os homens inventam sua própria língua a cada instante e cada um de uma maneira distintiva, e cada vez de uma maneira nova" (BENVENISTE, 1974/1989, p. 18).

A constatação de que o homem não nasceu falante, mas que tem uma potência para tal, marca o processo de aquisição da linguagem e inaugura a infância na linguagem de cada falante como possibilidade de se historicizar no seu próprio discurso. Por isso, o estudo proposto dialoga com dois deslocamentos da reflexão benvenistiana sobre linguagem: a Teoria da Infância, proposta por Agamben (2008), e a Invenção do Discurso, teorizada por Dessons (2006). Ambas as propostas permitem pensar o modo como o homem, por nascer na cultura
(BENVENISTE, 1966/1995; 1974/1989), historiciza-se na linguagem, visto ter, a cada ato de enunciação (de escrita, de leitura, de oralidade e de escuta), que se deparar com a transformação do domínio da língua em domínio de discurso. Nessa passagem, o homem inscreve sua história em uma experiência de linguagem com outros para se instaurar como sujeito e ser histórico, já que pensar a língua em si e por ela mesma, fora de seu emprego, é excluir o humano e o histórico.

Com a ideia de que o homem, por estar imerso na linguagem, reinventa sua língua a cada ato de enunciação - falado e escrito - organizamos este texto em duas partes: na primeira, é apresentada uma concepção de linguagem atrelada a seu funcionamento simbólico e indissociável da dimensão humana; na segunda parte, é tratada a relação entre a aquisição inicial e a escrita-leitura na Universidade com a ilustração da relação do homem com a língua em momentos distintos - uma criança instaurando-se na língua falada e um aluno universitário em processo de mudança de sua relação com a escrita e com a leitura para, posteriormente, ser constituída uma reflexão sobre aquisição da língua oral pela criança e sobre os processos de escrita e leitura, na universidade, como processos contínuos porque vinculados à ocupação pelo homem de novos lugares enunciativos.

\section{A experiência de significação na língua-} discurso: o funcionamento simbólico da linguagem

Colocar a língua em emprego é instaurar um lugar para significar. A experiência de significação na e pela linguagem remete-nos à teorização de Benveniste (1966/1995; 1974/1989), visto, para o autor, não ser possível separar o homem da linguagem, o que o leva a desconstruir a oposição natureza e cultura e a defender que a linguagem está na natureza do homem. Dessons (2006), valendo-se dessa relação homem-linguagem, argumenta que, na reflexão benvenistiana, a linguagem é definida no homem e o homem na linguagem. Deslocando tal 
questão para o contexto deste artigo, concebemos que o simbolismo, articulador do homem à linguagem, está na base da significação e é condição de inscrição da criança em sua língua materna e de continuidade de ocupação de espaços de enunciação nessa língua, por meio de discursos sempre novos, que, como atos de enunciação, trazem acontecimentos diferentes que dão existência ao sujeito, fundando-o, a cada apropriação da língua, na linguagem.

Refletir sobre o processo de aquisição e ensino-aprendizagem de Língua Portuguesa nessa perspectiva é situar-se nessa dimensão de historicidade, conforme Dessons (2006), para tratar cada experiência de conversão da língua em discurso como um registro humano na linguagem, já que pensar a língua fora de seu uso é excluir o humano e o histórico.

Tal reflexão encaminha-nos a pensar no modo como a criança, por nascer na cultura (BENVENISTE, 1966/1989; 1974/1989), historiciza-se na linguagem, visto ter de, a cada ato de enunciação, deparar-se com a transformação da língua, ainda em aquisição, em discurso. Silva (2009, p. 286), ao se situar nessa perspectiva enunciativa, formula uma explicação para o processo de aquisição da linguagem: "A criança produz uma história de suas enunciações, por meio da qual constitui sua língua materna e o sistema de representações de sua cultura, estabelecendo-se, desse modo, como sujeito de/na linguagem". Essa formulação pode ser deslocada também para o contexto de aprendizagem de língua materna: o aluno produz uma história de suas enunciações, por meio da qual continua a se constituir em sua língua materna e no sistema de representações de sua cultura, estabelecendo-se, desse modo, como sujeito de/na linguagem.

Essas formulações podem ser
redimensionadas, neste texto, a partir da Teoria da Infância - proposta por Agamben (2008) - e da Invenção do Discurso - teorizada por Dessons (2006) -, porque ambos enfatizam a importância da reflexão de Benveniste sobre linguagem, por tratar o discurso como lugar em que o homem e a linguagem encontram seu ponto de indissociabilidade. Para Agamben (2008), experienciar-se na linguagem é reentrar na infância como o lugar de hiato entre língua e discurso, espaço necessário para o homem poder fazer a passagem de locutor a sujeito. Nesse sentido, a infância não está localizada em um tempo "antes" da linguagem, mas se situa justamente na cisão e na diferença entre língua e discurso. Por isso, torna-se interessante refletir sobre o modo como cada homem inscreve o lugar dessa diferença, lugar que parece ser inaugurado na passagem de infans (de quem não fala) a falante, momento em que a criança se inscreve em sua língua materna por meio de seu ato de aquisição da linguagem.

Nessa direção, Dessons (2006) defende que a enunciação funda a historicidade do homem na linguagem, já que cada falante se individualiza na instância de discurso sempre nova e irrepetível. Isso porque o discurso, conforme Benveniste (1966/1995; 1974/1989), é o acontecimento diferente que dá existência, a cada ato de enunciação, ao sujeito. Refletir sobre os processos de aquisição e aprendizagem de língua materna, implicados nos atos de falar, ouvir, ler e escrever, é situar-se nessa dimensão da infância do homem e de historicidade da linguagem para tratar cada experiência de enunciação como instauradora de uma história na linguagem.

É essa experiência humana inscrita na linguagem que possibilita ao aluno fazer renascer, a cada ato de enunciação, a sua presença na língua, que se reatualiza pela passagem do semiótico (mundo do signo e da língua) ao semântico (mundo da frase e do discurso), sendo possível, por essa reatualização, historicizar-se na linguagem. Como nos lembra Agamben (2008, p. 68, grifos do autor): "o humano propriamente nada mais é que esta passagem da pura língua ao discurso; porém este trânsito, este instante, é a história. " É uma história que existe somente na instanciação do discurso e inscreve o sujeito nesse acontecimento.

De uma enunciação a outra, o sujeito, que é de linguagem, constitui-se de novo. Tem-se nessa formulação, para Dessons (2006), o princípio de 
reinvenção, que comporta a historicidade da linguagem e do sujeito, visto a repetição não se produzir de modo idêntico. Sentidos singulares, instanciados no discurso, deixam os registros, na linguagem, do homem. Nesse caráter radicalmente histórico, o locutor instancia-se como sujeito na linguagem, ao reorganizar suas enunciações para significar sempre de modo novo.

Por isso, pensar que nós, a cada nova experiência de uso de língua, ressignificamos o fato de que somos seres falantes, ouvintes, escreventes e leitores é também pensar que, nessa experiência sempre nova, deparamo-nos com a transformação do domínio do signo em domínio de discurso para significarmos essa experiência na e pela linguagem.

Considerar a aquisição da linguagem como um fenômeno constitutivo do saber do homem sobre sua própria língua significa conceber a linguagem como própria do humano, uma vez que os dados de experiência só são apreendidos pela capacidade simbólica humana, base das funções conceptuais. É em Benveniste que encontramos ancoragem para essa reflexão:

$\mathrm{Na}$ verdade, o homem não foi criado duas vezes, uma vez sem linguagem, e uma vez com linguagem. A ascensão de Homo na série animal pode haver sido favorizada pela sua estrutura corporal ou pela sua organização nervosa; deve-se antes de tudo à sua faculdade de representação simbólica, fonte comum do pensamento, da linguagem e da sociedade.

Essa capacidade simbólica está na base das funções conceptuais. (BENVENISTE, 1966/1995, p. 29) [grifos nossos].

Como a linguagem representa a principal faculdade inerente à condição humana, a de simbolizar, essa faculdade simbolizante permite-nos estabelecer relações de significação necessárias para transitarmos do mundo da língua para o mundo do discurso. As diferentes relações de significação presentes na relação do homem com sua línguadiscurso, que são constitutivas do funcionamento simbólico da linguagem, manifestam-se na distintividade (a que essa forma se opõe? Ser distintivo é ser significativo); no reconhecimento (essa forma tem sentido no uso?); na compreensão da ideia constituída no discurso (qual o sentido desse discurso?). É nesse jogo entre distintividade, reconhecimento e compreensão que o falante está imerso sempre para significar e comunicar com e para o outro. Essas reflexões são constitutivas dos atos de enunciação em diferentes situações de convívio com a linguagem e possibilitam que se pense a conversão da língua em discurso como uma reinvenção e como um processo contínuo e inacabado. "Se o próprio da linguagem é, antes de tudo, significar" (BENVENISTE, 1974/1989, p. 222), é próprio do homem significar sua experiência por meio da inserção de seu discurso no mundo, inserção que está na dependência do modo como a língua é atualizada e simbolizada nas diferentes instâncias culturais de que faz parte.

Não há relação natural, imediata e direta entre o homem e o mundo, nem entre o homem e o homem; é preciso haver um aparato simbólico para intermediar essa relação. A linguagem, como sistema simbólico por excelência, é o elo intermediário homem-mundo e homem-homem, por se realizar em uma língua particular inseparável de uma sociedade com sua cultura. Nesse sentido, o discurso, como atualização da língua, manifesta o sistema de valores de dada cultura inerente a cada instância social, e carrega certa herança linguístico-cultural, pois tanto a língua quanto a sociedade nos são dadas. Ainda que nos sejam dadas, também uma e outra são apreendidas. É essa apreensão constante que consideramos estar em jogo nas instâncias de aquisição e de ensino aprendizagem de língua materna, visto a entrada do falante em novas situações de convívio com a linguagem pela necessidade de referir requerer apreensões distintas da língua, seja falada, seja escrita.

Cada indivíduo manifesta o simbolismo cultural em que se encontra imerso por meio da língua em emprego, o que faz Benveniste (1974/1989, p. 24) defender que a língua se constitui como "um mecanismo de significação", por haver "uma semântica que atravessa todos esses elementos de cultura e que os organiza." (BENVENISTE,1974/1989, p. 25). Por isso, afirma: "tudo que é do domínio da 
cultura deriva no fundo de valores, de sistema de valores. Da articulação entre valores. [...] Esses valores são os que se imprimem na língua". (BENVENISTE, 1974/1989, p. 22).

A dupla condição de significar da língua, nos domínios do signo e do discurso, permite-lhe ser o sistema interpretante por excelência, seja de outros sistemas, seja dela mesma. Valer-se da língua como sistema interpretante de outros é estar em um lugar de constante reinvenção de discurso, lugar em que cada falante pode continuar sua história de enunciações e se fundamentar como sujeito na linguagem.

Estar em uma língua materna é presentificarse na dimensão de significância do discurso e na dimensão de significância translinguística - dos textos, das obras -, fenômeno que Benveniste (1974/1989, p. 67) denomina metassemântica. É a partir dessas dimensões de significância, que pretendemos refletir sobre o processo de aquisição e de contínua aprendizagem da língua materna. É por essa perspectiva que situamos cada experiência na linguagem (seja da criança em aquisição, seja do aluno em sala de aula em distintos contextos) como instauradora de uma história, de falante, de ouvinte, de escritor e de leitor, questão a ser tematizada na seção seguinte.

\section{A experiência humana na linguagem na passagem da língua ao discurso: da aquisição ao ensino de língua materna}

Tematizar a língua convertida em discurso requer pensar nos modos como um saber e uma experiência na linguagem são produzidos na nossa cultura e seus efeitos nas enunciações externas e internas à sala de aula. Que história de enunciações cada aluno carrega? Como o trabalho com língua materna poderá permitir que 0 aluno continue produzindo um saber sobre a língua e se historicizando na linguagem?

No âmbito das discussões sobre ensino no país, é pressuposto consensual que as práticas de ensino de Língua Portuguesa precisam partir do uso para tomar a língua em emprego como objeto de reflexão, não na forma de memorização de nomenclaturas, mas de entendimento do funcionamento linguístico e interlocutivo de textos.

Para a constituição do aluno como um produtor de saberes sobre sua língua e como continuador de sua história de enunciações, torna-se relevante que sejam garantidos, em sala de aula, espaços para o enunciar. É dialogando com discursos (ouvindo e lendo) e produzindo discursos (falando e escrevendo) que o homem pode reencontrar a língua com seu aparato simbólico, pois de outro modo não teria como estar na linguagem. "Se bem antes de servir para comunicar, a linguagem serve para viver' (BENVENISTE, 1974/1989, p. 222, grifo do autor) é porque o processo de troca é o que remete a experiência humana inscrita na linguagem a cada (re) invenção do discurso, visto que não dispomos de nenhum outro meio de viver na linguagem senão "pela inserção do discurso no mundo" (BENVENISTE, 1974/1989, p. 85). Por isso, somos instigados a responder como o falante/ouvinte/escrevente/leitor (seja a criança em aquisição em situações espontâneas; seja o aluno em sala de aula) insere seu discurso no mundo para manifestar a sua experiência na linguagem.

Retomamos o nosso questionamento inicial como os processos de falar-ouvir e ler-escrever, avessos um do outro, constituem o aluno na língua materna? - para inserirmos novas questões: em sala de aula, trabalham-se constantemente os atos de enunciação de falar, ouvir, escrever e ler como interdependentes? É possível constituir em sala de aula um ensino produtivo em língua materna sem a integração desses atos, avessos um do outro? Quem torna, em sala de aula, esses atos interdependentes? Quem está na origem desses atos? Como os falantes, ouvintes, leitores e escreventes integram forma e sentido em sala de aula nesses atos para fazerem a passagem de locutores a sujeitos?

Considerando que o emprego da língua implica a integração da relação forma e sentido em todos os níveis e unidades e a passagem de locutor a sujeito, em que os valores da cultura se imprimem na língua- 
discurso nas distintas instâncias sociais, torna-se interessante flagrar instantes em que falantes/ouvintes/escreventes/leitores tomam a língua como interpretante de si mesma e de outros sistemas para se situarem no que Benveniste (1974/1989) denomina metassemântica e revelarem a dualidade da língua em emprego, que é imanente ao indivíduo e transcendente à sociedade em que vive.

Nesse caso, apropriar-se da língua envolve a apropriação de um sistema articulado de unidades na forma e no sentido, com valores culturais impressos nessas unidades. Tais valores comparecem no discurso e traduzem a experiência humana na linguagem, revelando simultaneamente a significância dos signos e a significância dos discursos.

Como a dualidade (imanência ao indivíduo e transcendência à sociedade) se reencontra em todas as propriedades da língua, conforme Benveniste (op. cit.), olhar para os fatos enunciativos, nessa perspectiva, é refletir sobre como cada falanteouvinte/escrevente-leitor "apropria-se da linguagem e dos dados culturais que se considera que ela traduz" (BENVENISTE, op.cit., p. 22). Por distinguir o que tem sentido e o que não tem, a cultura manifesta-se no discurso, mas carregando os valores culturais impressos nas unidades da língua. Destacamos aqui alguns instantes interessantes dessa relação dos falantes com a sua língua materna e com o outro.

Quadro 1: Fato enunciativo de criança em Aquisição da Linguagem

Participantes: Gustavo (CRI - criança informante), pai (PAI) e Alessandra (OBS.- observadora participante) Idade da criança: 2;0

Situação: Gustavo e pai estão na sala assistindo televisão e brincando com cartas de baralho em atividades de nomeação/identificação dos nomes das gravuras.

PAl: olha cada jipão

CRI: vira-se para olhar para TV

PAl: olha esse aqui é o caRRÃO [= pai alonga os segmentos finais da palavra pronuncia em tom ascendente, enfatizando a sonoridade]
CRI: caRRÃO [= criança alonga os segmentos finais e enfatiza a sonoridade da vibrante]

PAI: caRRÃO [= pai alonga os segmentos finais da palavra em tom ascendente e enfatiza a sonoridade da vibrante com mais intensidade, reforçando a relação da pronúncia da forma ao barulho do carro]

CRI: e ipe

PAI: jipe de novo, outro jipe

CRI: oto jipe?

PAl: e esse aqui?

CRI: dadô? [= pronúncia com uma entonação ascendente de dúvida]

PAl: e esse?

Fonte: Banco de linguagem da criança do Projeto NaLíngua, coordenado por Alessandra Dal Ré

Como a criança, em relação com o outro, valese do seu aparelho vocal para se instaurar no jogo de nomeações e se integrar à sua cultura? $\mathrm{O}$ fato enunciativo da criança é revelador dessa integração e possibilita fundamentar a argumentação de que a possibilidade de a criança encontrar sua língua materna e nela se instaurar está na faculdade benvenistianas, que se centra no fato de que a existência do homem na linguagem está atrelada a humana de simbolizar (BENVENISTE, 1966/1995; 1974/1989). E, aqui, retomamos uma das teses benvenistianas, que se centra no fato de que a existência do homem na linguagem está atrelada a seu nascimento na cultura:

E se digo que o homem não nasce na natureza, mas na cultura, é que toda criança e em todas as épocas, na pré-história a mais recuada como hoje, aprende necessariamente com a língua os rudimentos de uma cultura. Nenhuma língua é separável de uma função cultural. [...] (BENVENISTE, 1974/1989, p. 23/24)

É a condição humana de simbolizar que encaminha a criança a nomear e ao outro a significar seus atos de nomeação para construírem lugares de enunciação que registram os movimentos desses sujeitos na linguagem. Por meio do modo como se valem do aparelho vocal, para expressarem certa 
relação com o mundo, ao atualizarem nomes no discurso com modos de vocalizar próprios à situação de brincar com gravuras, a criança e seu pai "falam de" e evocam os rudimentos de cultura impressos na língua. O modo como nomeiam carro traz os vestígios dos valores culturais que imprimem a essa forma.

O nome, enquanto atualização do que não faz parte das pessoas do discurso (eu-tu), é o que possibilita a cada locutor estar e integrar-se na língua e, consequentemente, no simbolismo da linguagem. O nome, enquanto face mais aparente da operação de referência, garante a "possibilidade de discurso sobre alguma coisa, sobre o mundo, sobre o que não é da alocução" (BENVENISTE, 1974/1989, p. 101). Ao nomear com especificidades vocais, cada locutor instancia no discurso a referência como produto e efeito de sua enunciação.

Vemos, no fato enunciativo do quadro 1, o pai como aquele que concede um lugar de enunciação para a criança e também como aquele que representa a língua e a cultura como instituições sociais. É pelo discurso do pai que a criança assimila valores culturais às formas que enuncia. Nesse caso, muito mais do que "falar de" ou referir pelo discurso estão em jogo os sentidos evocados na relação intersubjetiva por meio do modo singular de atualização do aspecto vocal nos discursos do pai e da criança.

A compreensão dos sentidos do discurso está para além das unidades e o vocal ganha saliência para historicizar a subjetividade da criança na linguagem a partir da intersubjetividade, pois é o pai quem nomeia a figura e atualiza a forma "carrão" com alongamento vocálico da sílaba final e a entonação ascendente, pronúncias combinadas com a ênfase no fonema vibrante [r]. A criança retoma esse modo de pronúncia com pouco menos intensidade e o pai volta a repetir a forma com mais ênfase na sonoridade da vibrante. Nessa inversibilidade enunciativa em que se presentifica a forma "carrão" nos discursos, tem-se sentidos particulares às formas dessa palavra que se instauram nessa relação eu-tu. Nesse caso, não é somente o sentido intralinguístico da forma enquanto signo da língua que ganha saliência nessa comunicação intersubjetiva, mas o sentido que enlaça um discurso no outro (do pai e da criança) para evocar o barulho do carro, sua beleza e sua potência. Tais valores culturais estão integrados nos modos de vocalizar do pai e do Gustavo.

O sufixo "-ão" é reconhecido como pertencente à língua, mas a compreensão da singularidade de seus sentidos se constitui pelo modo como é vocalizado. $O$ fato de o pai e a criança mobilizarem o vocal com determinadas especificidades registra a história desse nome na língua-discurso de Gustavo. É a instância de discurso constituindo $o$ ato $e$ concomitantemente fundamentando o sujeito em seu movimento singular de apreensão do sistema da língua e do sistema cultural impresso nas unidades dessa língua-discurso.

Vemos, portanto, o aspecto vocal da enunciação como transversal à interdependência entre a emissão e a percepção. Essa interdependência instancia a intersubjetividade constitutiva da linguagem e registra os atos de emissão oral e de percepção como avessos um do outro, fundamentando o questionamento inicial deste trabalho.

No fato enunciativo de entrada do aluno na Universidade (Quadro 2), há uma queixa que está na busca de um uso da língua como prática significativa para a vida, pois a falta de reconhecimento de si como autor de sua escrita escolar está relacionada à falta de interlocutor que o reconheça como tal. Por isso, busca um interlocutor que se presentifique em um ato avesso ao de sua escrita, um locutor-leitor. No fato enunciativo do aluno com vivência na Universidade (Quadro 3), vemos uma busca de apreensão da língua como interpretante de outros sistemas (projeto arquitetônico) para comunicar uma ideia para o outro e tornar seu ato de escrita avesso de outro ato, o de leitura. 
Quadro 2: Fato enunciativo de um aluno universitário em sua entrada na Universidade ${ }^{1}$

"Quando eu escrevo uma redação, não consigo me enxergar nela, mas quando eu escrevo em conversas virtuais até meus amigos sabem que sou eu quem está escrevendo." (PAG-Leitura e produção de textos em Língua Portuguesa, 2010).

Fonte: Junchem (2012)

Quadro 3: Fato enunciativo de aluno universitário com vivência na universidade

"Preciso aprimorar minha capacidade de uso da língua para explicar a outros os projetos arquitetônicos que produzo, ou seja, para traduzir a ideia que carrega."

Fonte: PAG-Leitura e produção de textos em Língua Portuguesa, semestre 2015-2.

Da aquisição da criança ao ensinoaprendizagem de língua materna do fundamental à Universidade está implicada a instauração do homem nos sentidos sociais da língua em uso nas distintas situações. E as "queixas" e as "buscas" dos alunos universitários são reveladoras do continuum da aquisição e da importância que concedem ao interlocutor para continuarem inventando sua própria língua nos atos "avessos" da língua (atos de falarouvir/escrever-ler) e experienciando-se historicamente na linguagem.

A relação que o homem estabelece com 0 mundo e com o outro somente é possível pela linguagem por meio de relações de interpretância, em que a língua figura como sistema interpretante por excelência porque comporta, em sua estrutura e em seu funcionamento, quatro aspectos: 1) a possibilidade de manifestação pela enunciação para constituir referência a uma situação dada (produzir sentido no discurso); 2) unidades em relação; 3) os valores partilhados pelos membros de uma comunidade (compreensão vinculada à instância

\footnotetext{
${ }^{1}$ Os discursos de alunos universitários analisados neste artigo são oriundos do Programa de Apoio à Graduação (PAG) Projeto Leitura e Produção de Textos em Língua Portuguesa, que consiste em oferecer aos alunos de graduação, através da forma de oficinas de leitura e produção de textos, a busca de qualificação do desempenho no uso da Língua Portuguesa, principalmente escrita.
}

cultural impressa na língua-discurso); e 4) o lugar de atualização da comunicação intersubjetiva.

Esses aspectos fundamentam a experiência humana na linguagem, que é uma experiência de significação e embasam os discursos dos alunos universitários nos fatos enunciativos dos quadros 2 e 3. Por isso, para que o aluno ressignifique, em apropriações individuais e singulares da língua - seja falada, seja escrita -, sua relação com a linguagem e se funde no aparato simbólico de sua língua nas diferentes instâncias de passagem do mundo do signo ao mundo do discurso, é fundamental a existência de outro que lhe conceda um lugar de enunciação, convocando-o a se enunciar, como vemos no fato enunciativo do ato de aquisição da linguagem pela criança.

Nesse caso, é fundamental em sala de aula valorizarmos a história de relações do aluno com o seu mundo e com o uso da língua para ressignificálas. A nossa "escuta" atenta e atuante, ao significar as falas dos alunos em sala de aula, ganha importância como o elo que nos possibilita criar atividades de produção escrita e leitura de textos com a constituição de contextos que convoquem o aluno a colocar a língua em emprego e o levem a ocupar um lugar de enunciação, sempre único e renovado e, com isso, continue sua história de enunciações na linguagem, iniciada no ato de aquisição: "os caminhos da enunciação permitem o encontro da criança com a língua. Encontro esse que não cessa de acontecer, por meio de "trilhas" sempre novas, reinventadas durante toda a vida." (SILVA, 2009, p, 287).

\section{Palavras finais}

A língua somente tem vida ao se refazer a cada instância de uso. Tornar a língua própria é o aspecto constitutivo do próprio ato de enunciar, seja no de falar, seja no de ouvir, seja no de escrever, seja no de ler. Ensinar língua portuguesa é possibilitar ao aluno estar no funcionamento simbólico da linguagem com outros. Afinal, somente podemos viver experiências na linguagem se colocarmos a língua em uso por meio de sua conversão em discurso para 
fundamentar as suas duas modalidades fundamentais: a de significar e a de comunicar para e com outros.

A experiência humana de significação na linguagem, por meio do aspecto vocal, é o que permite à criança historicizar-se na dupla natureza de sua língua materna (individual e social). Essa história não cessa de acontecer por meio de atos de enunciação falados e escritos e em seus avessos (atos de escuta e de leitura). Como o homem para viver na linguagem necessita inserir a palavra no mundo, essa vivência é inaugurada no ato de aquisição de linguagem e continua existindo a cada invenção de discurso.

\section{Referências}

AGAMBEN, Giorgio. Infância e história: destruição da experiência e origem da história. Belo Horizonte: Editora UFMG, 2008.

BENVENISTE, Émile. (1966). Problemas de Linguística Geral I. 4. ed. Campinas, SP: Pontes, 1995.

(1974). Problemas de Linguística Geral II. Campinas, SP: Pontes, 1989.

(2012). Últimas aulas no Collège de France. São Paulo: Editora da UNESP, 2014.

DESSONS, Gérard. Émile Benveniste: I'inventions du discours. Éditions in Press: Paris, 2006.

JUCHEM, Aline. Por uma concepção enunciativa da escrita e re-escrita de textos em sala de aula: os horizontes de um hífen. Dissertação (Mestrado em Estudos da Linguagem). Universidade Federal do Rio Grande do Sul. Instituto de Letras, Programa de PósGraduação em Letras, 2012.

SILVA, Carmem Luci da Costa. A criança na linguagem: enunciação e aquisição. São Paulo: Pontes, 2009. 